Tropical Journal of Pharmaceutical Research September 2017; 16 (9): 2221-2229

ISSN: 1596-5996 (print); 1596-9827 (electronic)

(C) Pharmacotherapy Group, Faculty of Pharmacy, University of Benin, Benin City, 300001 Nigeria.

All rights reserved.

Available online at http://www.tjpr.org

Original Research Article

http://dx.doi.org/10.4314/tjpr.v16i9.25

\title{
Antioxidant, antimicrobial and antiproliferative activities of peel and pulp extracts of red and white varieties of Ipomoea batatas (L) Lam
}

\author{
Shakeela Naz', Syed Ali Raza Naqvi ${ }^{1 *}$, Zulfiqar Ali Khan ${ }^{1}$, Asim Mansha1, \\ Matloob Ahmad", Ameer Fawad Zahoor ${ }^{1}$ and Zaib Hussain ${ }^{2}$ \\ ${ }^{1}$ Department of Chemistry, Government College University, Fiasalabad-38040, ${ }^{2}$ Institute of Chemistry, University of the Punjab, \\ Lahore-54000, Pakistan \\ *For correspondence: Email: draliraza@gcuf.edu.pk, drzh_1972@hotmail.com; Tel: +92-300-4118207, +92-334-4396809
}

\begin{abstract}
Purpose: To investigate the antioxidant, antibacterial and anticancer potentials of methanol and ethanol extracts of the peel and pulp of red and white species of Ipomoea batatas (L.) fruit.

Methods: Total phenolic contents and flavonoids were determined using chemical assays. Antioxidant studies were carried out using 2,2-diphenyl-1-picrylhydrazyl (DPPH) free radical scavenging assay, inhibition of linoleic acid peroxidation assay and reducing power assay. Antibacterial and antiproliferative activities of extracts were determined using disc diffusion and MDBK cancer cell line inhibition methods, respectively.

Results: The extract of peels of red specie (PERS) showed total phenolic contents (TPC) 8.9 mg gallic acid equivalent (GAE)/g dry extract and flavonoids $6.5 \mathrm{mg}$ catechin equivalent $(C E) / g$ dry extract. The extract of PERS also showed promising DPPH free radical scavenging activity, inhibition of linoleic acid peroxidation and reducing power activity. However, mild antibacterial and anti-proliferative activities were noted except that the extract showed significant inhibition of Bacillus subtilis growth.

Conclusion: The results indicate that the peel and the pulp of red sweet potato (SP) specie are rich in antioxidants and can potentually be processed as antioxidant food supplements.
\end{abstract}

Keywords: Ipomoea batatas (L.) Lam, Sweet potato, Phenolic content, Antioxidants, Antibacterial activity, Antiproliferative activity

Tropical Journal of Pharmaceutical Research is indexed by Science Citation Index (SciSearch), Scopus, International Pharmaceutical Abstract, Chemical Abstracts, Embase, Index Copernicus, EBSCO, African Index Medicus, JournalSeek, Journal Citation Reports/Science Edition, Directory of Open Access Journals (DOAJ), African Journal Online, Bioline International, Open-J-Gate and Pharmacy Abstracts

\section{INTRODUCTION}

The role of antioxidants is important in fixing the conditions such as heart, cancer, chronic inflammation and Alzheimer's diseases which arose due to the oxidative cell damage. Inflammation alone may initiate variety of diseases including vasculitis, lupus erythematous, glomerulonephritis, adult respiratory diseases syndrome, and arthritis. Oxidative stress or cell damage may also involves in many other kinds of chronic diseases such as ischemic diseases (stroke, heart diseases, intestinal ischema), acquired immunodeficiency syndrome (AIDS), hemochromatosis, hypertension emphysema, gastric ulcers, organ transplantation, preeclampsia, neurological disorder (muscular dystrophy, Alzheimer's disease, Parkinson's disease), smoking-related diseases, and alcoholism [1].

Antioxidants can effectively reduce the oxidative stress and consequently the risk of chronic 
diseases. Antioxidants, which are mainly obtained from two major sources i.e., extraction from natural sources and by chemical synthesis are being used as preventive or therapeutic medicines. The later source may cause severe toxicity such as genotoxicity, carcinogenicity or hepatotoxicity [2].

The reports of several studies have demonstrated that natural antioxidants offer high potential in the prophylaxis and treatment of some oxidative damage diseases, resulting in the reduction of mortality rate [3]. Therefore, the search for antioxidant, antibacterial and anticancer potential of natural plant components and isolation of natural antioxidants is of fundamental interest of natural product chemistry scientists. Extraction, isolation and purification of natural products have been translated into a drug development process. About $50 \%$ pharmaceuticals currently in use are derived from natural products [4]. The discovery of anticancer drugs such as vinca alkaloids, etoposide, paclitaxel, and variety of antimicrobial drugs encourage drug-discovery programs [5].

Ipomoea batatas (L.) Lam (SP) is an important fruit belonging to the family Convolvulaceae, and is well known to consumers for its nutritional values and sweet taste [6]. Initially, it was cultivated in Central America but later on due to its wide adaptability to various climates and farming systems, it has now been cultivated throughout the world and being studied for its medicinal potential $[6,7]$. In view of the nutritional benefits of SP, the aim of this study was to investigate the antioxidant, antibacterial and anticancer activities of red and white varieties of SP. Therefore, the aim of this study was to assess the antioxidant, antibacterial and anticancer potentials of the methanol and ethanol extracts of peel and pulp of red and white varieties of SP

\section{EXPERIMENTAL}

\section{Materials}

Red and white SP tubers were collected from local farm houses situated in countryside of Faisalabad (Punjab), Pakistan. The tubers of both varieties were collected in December 2015. The authentication of the samples was carried out by Dr. M. Naeem (Taxonomist \& Associate Professor, Department of Botany, GC University, Faisalabad-Pakistan). The voucher specimens (No: GCUF/Bot-102 \& 103) were kept at herbarium of Department of Botany, GC University, Faisalabad, Pakistan. DPPH, linoleic acid, BHT were purchased from Sigma-Aldrich,
Germany. All other chemicals were purchased from BDH Chemicals UK. All chemicals were of analytical grade. Bacterial strains and MDBK cancer cell line were obtained from the University of Health Sciences, Lahore, Pakistan. Spectroscopic analyses were performed using double beam Spectrophotometer (Hitachi U2000, Japan) and Elisa reader (Bio-Rad Model 680, Hercules, CA, USA).

\section{Preparation of extracts}

The tubers of red and white varieties of SP were washed properly after collection with distilled water to remove soil contents. The peel and pulp of the fruit was separated and subjected to freeze drying. The dried material were stored at 4 ${ }^{\circ} \mathrm{C}$ for extraction processes. The biological components of peel and pulp were extracted in $95 \%$ methanol and ethanol solvents. The extraction was carried out by mixing $20 \mathrm{~g}$ freeze dried sample in $120 \mathrm{~mL}$ of extraction solvent in $250 \mathrm{~mL}$ conical flasks followed by shaking (200 rpm) at room temperature for $24 \mathrm{~h}$. After $24 \mathrm{~h}$, the contents of the flasks were filtered using Whatman no. 1 filter paper. The residue was again subjected to extraction process and the both filtrates were combined. The filtrates were concentrated using rotary evaporator at reduced pressure. The concentrated raw extracts were stored at $-4{ }^{\circ} \mathrm{C}$ for further analysis.

\section{Determination of total phenolics}

Total phenolic contents were determined using method described by Chaovanalikit and coworkers [8]. Briefly, dry extract $(50 \mathrm{mg})$ was mixed with $0.5 \mathrm{~mL}$ of Folin-Ciocalteu reagent and $7.5 \mathrm{~mL}$ of deionized distilled water in a test tube. The dissolved contents were kept at room temperature for $10 \mathrm{~min}$, followed by the addition of $1.5 \mathrm{~mL} \mathrm{NaCO}$ solution (20\%). The solution was then heated at $40{ }^{\circ} \mathrm{C}$ for $20 \mathrm{~min}$ and then cold in an ice bath. The absorbance of the cold solution was noted at $755 \mathrm{~nm}$ using a double beam UV-Vis spectrophotometer. The amount of TPC was estimated using a calibrated curve of gallic acid. The results were presented as GAE / $g$ dry extract. The experiments were performed in triplicate $(n=3)$ for each sample.

\section{Determination of total flavonoids}

Total flavonoid contents (TFC) were determined using the method described by Dewanto et al. with slight modification [9]. Briefly, dry extract $(0.01 \mathrm{~g})$ was dissolved in $1 \mathrm{~mL}$ of ethanol in a volumetric flask followed by the subsequent addition of $6.1 \mathrm{~mL}$ distilled water and $0.3 \mathrm{~mL}$ $\mathrm{NaNO}_{2}$ solution (5 \%). The mixture was 
incubated for $5 \mathrm{~min}$, after which $0.6 \mathrm{~mL}$ of $\mathrm{AlCl}_{3}$ $(10 \%)$ was added into the flask, gently shaked and then $2 \mathrm{~mL}$ of $\mathrm{NaOH}$ solution (1 N) was added. The absorbance of the solution was noted at $510 \mathrm{~nm}$ by a double beam UV-Vis spectrophotometer. The amount of TFC was expressed as CE / g dry extract.

\section{Determination of antioxidant activity}

The antioxidant potential of peel and pulp extracts was determined using DPPH free radical scavenging assay, inhibition of linoleic acid peroxidation assay and reducing power assay.

\section{Determination of DPPH free radical scavenging potential}

DPPH free radical scavenging potential of peel and pulp of SP extracts was assessed according to the method reported by Yen \& Chen [10]. To the $1 \mathrm{~mL}$ of DPPH solution (0.1 mM in ethanol) added $3 \mathrm{~mL}$ extract solution of varying concentration $(20,40,60,80$ and $100 \mu \mathrm{g} / \mathrm{mL})$ and the mixture was incubated in the dark for 30 min. Thereafter, the absorbance was measured by double beam UV-Vis spectrophotometer at $517 \mathrm{~nm}$. Synthetic antioxidant, BHT was taken as reference compound. Solution without extract was taken as negative control. DPPH free radical scavenging (D) was calculated using Eq 1.

$D(\%)=\left\{\left(A_{0}-A_{1}\right) / A_{0}\right\} 100$

where $A_{1}$ and $A_{0}$ are the absorbance of sample and blank solutions, respectively. The results are expressed as mean \pm standard deviation (mean $\pm S D, n=3$ ).

\section{Evaluation of inhibition of linoleic acid peroxidation}

Inhibition of linoleic acid peroxidation was measured using ammonium thoicyanate assay [11]. According to this assay, an aliquot of $0.2 \mathrm{~mL}$ of linoleic acid emulsion $(25 \mathrm{mg} / \mathrm{mL}$ in $99 \%$ ethanol) and $0.4 \mathrm{~mL}$ of $50 \mathrm{mM}$ phosphate buffer $(\mathrm{pH}$ 7.4) was subsequently added to $0.2 \mathrm{~mL}$ sample solution $(100 \mu \mathrm{g} / \mathrm{mL}$ in ethanol). The mixture was then incubated in dark at $40{ }^{\circ} \mathrm{C}$ for 24-h. At the end of incubation period, $0.1 \mathrm{~mL}$ reaction mixture was taken in the test tube and then added $3 \mathrm{~mL}$ ethanol $(70 \%)$ and $0.1 \mathrm{~mL}$ ammonium thiocyanate $(30 \% \mathrm{w} / \mathrm{v})$ solutions. The reaction mixture was then gently shaked and left to stand for $3 \mathrm{~min}$ at ambient temperature followed by then addition of $0.1 \mathrm{~mL}$ of ferrous chloride solution $(20 \mathrm{mM}$ in $3.5 \% \mathrm{HCl})$. Then the absorbance was immediately recorded spectrophotometrically at $500 \mathrm{~nm}$. The absorption of reaction mixture was noted after every 24-h unless the absorbance value of control reached to maximum value. A solution without extract was taken as negative control while $\mathrm{BHT}$ was used as reference.

\section{Determination of reducing power}

In this study, the reducing power of sample extracts was measured following the protocol described by Khan et al [11]. Briefly, the sodium phosphate buffer solution ( $5 \mathrm{~mL}, 0.2 \mathrm{M}, \mathrm{pH} 6.6$ ) and potassium ferricyanide $(5 \mathrm{~mL})$ was added to $100 \mu \mathrm{g}$ dry extract and left the mixture for incubation at $50 \stackrel{\circ}{\circ}$ for $20 \mathrm{~min}$. After that, $10 \%$ aqueous solution of trichloroaceic acid $(5 \mathrm{~mL})$ was added and the mixture was centrifuged at $980 \mathrm{~g}$ for $10 \mathrm{~min}$ at $-5^{\circ} \mathrm{C}$. The upper layer $(\sim 5$ $\mathrm{mL}$ ) of the mixture was separated in another test tube followed by the addition of $5 \mathrm{~mL}$ distilled water and $1 \mathrm{~mL}$ ferric chloride solution $(0.1 \%)$ which turned the color of the solution, yellow to green. The absorbance of the solution mixture was noted at $700 \mathrm{~nm}$. All samples were analyzed thrice $(n=3)$.

\section{Antibacterial assay}

Antibacterial activity was assessed using disc diffusion method. [12]. The extracts was screened against four bacterial strains; Escherichia coli, Pasturella multocida, Staphylococcus aureus, and Bacillus subtilis. In order to prepare the petri plates of microbes; nutrient agar $(28 \mathrm{~g} / \mathrm{L})$ was suspended in distilled water, mixed well and autoclaved at $121^{\circ} \mathrm{C}$ for $15 \mathrm{~min}$. Then the inoculums $(100 \mu \mathrm{L} / 100 \mathrm{~mL})$ were added to the medium and poured in sterilized petri plates. As the bacterial medium turned semisolid, the circular filter paper discs $(\sim 1.5 \mathrm{~mm}$ in diameter) loaded with $100 \mu \mathrm{L}$ of sample (2 $\mathrm{mg} / \mathrm{mL}$ in DMSO) were laid flat on the growth medium. DMSO and ciprofloxacin antibiotic were taken as negative and positive control, respectively. The petri plates were then incubated at $37^{\circ} \mathrm{C}$ for $24 \mathrm{~h}$. The extracts having antibacterial activity showed clear zones of inhibitions. The zones of inhibition were measured in millimeters using a zone reader.

\section{Antiproliferative assay}

Antiproliferative assay was performed using calorimetric method as described by Mosmann [13]. According to this method, $50 \mathrm{mg}$ of sample extract was dissolved in $500 \mu \mathrm{l}$ of Glasco Modified Eagle Medium (GMEM). The solution was thoroughly mixed in an eppendorf tube, vortexed and filtered with $0.4 \mu \mathrm{m}$ filter 
membrane. The filtered solution (20 $\mu \mathrm{L})$ was diluted to $200 \mu \mathrm{L}$ using GMEM in an eppendorf (solution A). In an each well of 96 well plate, 100 $\mu \mathrm{L}$ of media was poured using a micropipette followed by the addition of $100 \mu \mathrm{L}$ solution $A$ in the $1^{\text {st }}$ well. This was mixed to form solution $B$. From the $1^{\text {st }}$ well, $100 \mu \mathrm{L}$ of solution $B$ was transferred to the $2^{\text {nd }}$ well and the process was repeated to make subsequent dilutions. In this way two fold dilutions was prepared up to the $5^{\text {th }}$ well. The $6^{\text {th }}$ well of each row was used as a negative control. Following the dilution process, $100 \mu \mathrm{L}$ of cell suspension (MDBK) was poured in all wells with a multichannel micropipette and placed in $5 \% \mathrm{CO}_{2}$ incubator at $37{ }^{\circ} \mathrm{C}$ for $24-\mathrm{h}$. After 24-h, $20 \mu \mathrm{L}$ of 3-(4, 5-dimethyl thiazole-2yl)-2,5-diphenyl tetrazolium bromide (MTT) solution (5 mg / mL Phosphate Buffer Solution (PBS)) was added in all 96 wells. The plates were then placed in $5 \% \mathrm{CO}_{2}$ incubator at $37{ }^{\circ} \mathrm{C}$ for $3 \mathrm{~h}$ for the formation of Formazon crystals. At the end of the incubation period the solution from each well was decanted with a micropipette and the crystals were dissolved using $100 \mu \mathrm{L}$ of DMSO in each well resulting in a colored solution. The number of viable cells was directly proportional to the intensity of color. The absorption of the solution was recorded with ELISA reader (Bio-Rad Model 680) at $570 \mathrm{~nm}$.

\section{Statistical analysis}

All experiments were carried out thrice and the results were calculated as mean of triplicate values $(n=3) \pm$ standard deviation (SD).

\section{RESULTS}

The extraction yield of SP peel and pulp in methanol and ethanol was obtained in the range of $4.17 \%$ to $15.96 \%$ as shown in Table 1 . The highest yield of extract was obtained with methanol from PURS while lowest yield was obtained with methanol from PEWS.

\section{Total phenolic and flavonoid contents}

Table 2 shows TPC and TFC recorded in methanol and ethanol extracts of red and white variety of SP. Peels of red SP showed highest TPC and TFC, $8.9 \mathrm{mg}$ GAE and $6.5 \mathrm{mg} \mathrm{CE} / \mathrm{g}$ extract in ethanol, respectively. The same trend was also noted in methanol extracts of red SP peel which showed TPC and TFC, $4.6 \pm 0.2 \mathrm{mg}$ $\mathrm{GAE}$ and $3.8 \pm 0.1 \mathrm{CE} / \mathrm{g}$ extract, respectively. Extracts of PEWS, PURS and PUWS in both solvents showed good quantity of TPC; however, TFC were found low in these extracts. The TPC data is in agreement with previously reported data on TPC recorded in roots extracts of SP [14]. Pochapski et al also reported TPC in the range of 1.9 to $11.6 \mathrm{mg} \mathrm{GAE} / \mathrm{g}$ dry extract in leaves extracts of SP [15].

\section{DPPH free radical scavenging potential}

Table 2 shows the DPPH free radical scavenging potential of extracts. Most of the extracts showed promising free radical scavenging potential. Ethanol extract of PERS and methanol extract of PUWS showed high DPPH free radical scavenging potential i.e. $90.26 \%$ and $88.59 \%$, respectively. The reference synthetic antioxidant, BHT showed $72.36 \%$ scavenging potential. All other samples showed DPPH free radical scavenging potential less than $\mathrm{BHT}$ free radical scavenging potential.

\section{Inhibition of linoleic acid peroxidation}

The results of inhibition of linoleic acid peroxidation are shown in Figure 1.

The inhibition of linoleic acid peroxidation was investigated by measuring the absorbance of reaction mixture at $500 \mathrm{~nm}$. Greater the absorbance greater would be the inhibition of linoleic acid peroxidation. It was observed that

Table 1: Extraction yield (\%) of various extracts of SP

\begin{tabular}{lcccc}
\hline \multirow{2}{*}{$\begin{array}{l}\text { Extraction } \\
\text { solvent }\end{array}$} & \multicolumn{4}{c}{ Extraction yield (\%) } \\
\cline { 2 - 5 } & Red variety of SP & White variety of SP \\
\hline Methanol & Peel & Pulp & Peel & Pulp \\
Ethanol & 4.73 & 15.96 & 4.17 & 9.01 \\
& 8.44 & 7.68 & 6.45 & 7.72 \\
\hline
\end{tabular}

Table 2: TPC and TFC of methanol and ethanol extracts of red and white variety of SP

\begin{tabular}{lcccccccc}
\hline \multirow{2}{*}{ Biologics } & \multicolumn{10}{c}{ Extract } \\
\cline { 2 - 9 } & $\begin{array}{c}\text { PERS } \\
\text { MeOH }\end{array}$ & $\begin{array}{c}\text { PERS } \\
\text { EtOH }\end{array}$ & $\begin{array}{c}\text { PEWS } \\
\text { MeOH }\end{array}$ & $\begin{array}{c}\text { PEWS } \\
\text { EtOH }\end{array}$ & $\begin{array}{c}\text { PURS } \\
\text { MeOH }\end{array}$ & $\begin{array}{c}\text { PURS } \\
\text { EtOH }\end{array}$ & $\begin{array}{c}\text { PUWS } \\
\text { MeOH }\end{array}$ & $\begin{array}{c}\text { PUWS } \\
\text { EtOH }\end{array}$ \\
\hline TPC $(\mathrm{mg} / \mathrm{g})$ & $4.6 \pm 0.2^{*}$ & $8.9 \pm 0.2$ & $2.7 \pm 0.3$ & $2.6 \pm 0.1$ & $3.1 \pm 0.3$ & $1.5 \pm 0.0$ & $2.9 \pm 0.2$ & $1.5 \pm 0.2$ \\
TFC $(\mathrm{mg} / \mathrm{g})$ & $3.8 \pm 0.1$ & $6.5 \pm 0.1$ & $0.7 \pm 0.0$ & $1.6 \pm 0.1$ & $1.9 \pm 0.1$ & $0.8 \pm 0.1$ & $0.5 \pm 0.1$ & $0.2 \pm 0.0$ \\
\hline
\end{tabular}

Data shown are mean $\pm S D(n=3)$ 
Table 3: DPPH free radical scavenging activity of methanol and ethanol extracts of red and white variety of SPs at different concentrations

\begin{tabular}{lrrrrr}
\hline \multirow{2}{*}{ Extract } & \multicolumn{5}{c}{ Concentration $(\boldsymbol{\mu g} / \mathbf{m L})$} \\
\cline { 2 - 6 } & $\mathbf{2 0}$ & $\mathbf{4 0}$ & $\mathbf{6 0}$ & $\mathbf{8 0}$ & $\mathbf{1 0 0}$ \\
\hline PERS MeOH & $8.34 \pm 1.23^{*}$ & $11.73 \pm 1.70$ & $13.86 \pm 0.78$ & $15.02 \pm 1.34$ & $17.44 \pm 1.21$ \\
PERS EtOH & $54.15 \pm 1.95$ & $65.67 \pm 2.16$ & $77.79 \pm 2.09$ & $87.76 \pm 3.72$ & $90.26 \pm 4.32$ \\
PEWS MeOH & $43.84 \pm 2.54$ & $46.65 \pm 1.24$ & $53.48 \pm 2.56$ & $55.47 \pm 2.12$ & $60.38 \pm 2.58$ \\
PEWS EtOH & $7.86 \pm 0.99$ & $16.25 \pm 1.03$ & $25.32 \pm 1.33$ & $34.55 \pm 1.94$ & $43.54 \pm 1.96$ \\
PURS MeOH & $2.90 \pm 0.18$ & $4.02 \pm 0.53$ & $4.44 \pm 0.71$ & $5.32 \pm 0.63$ & $6.75 \pm 0.93$ \\
PURS EtOH & $1.28 \pm 0.31$ & $3.16 \pm 0.69$ & $5.04 \pm 0.43$ & $6.92 \pm 0.89$ & $9.47 \pm 1.07$ \\
PUWS MeOH & $54.86 \pm 2.31$ & $65.67 \pm 2.52$ & $77.19 \pm 3.75$ & $86.69 \pm 3.83$ & $88.59 \pm 3.52$ \\
PUWS EtOH & $5.70 \pm 1.07$ & $7.02 \pm 0.71$ & $8.55 \pm 1.16$ & $9.26 \pm 1.03$ & $10.09 \pm 0.84$ \\
BHT & $58.79 \pm 2.39$ & $62.81 \pm 2.41$ & $65.32 \pm 3.58$ & $68.34 \pm 2.17$ & $72.36 \pm 3.61$ \\
\hline
\end{tabular}

$\mathrm{MeOH}=$ methanol; EtOH = ethanol; *Values are mean $\pm S D(n=3)$
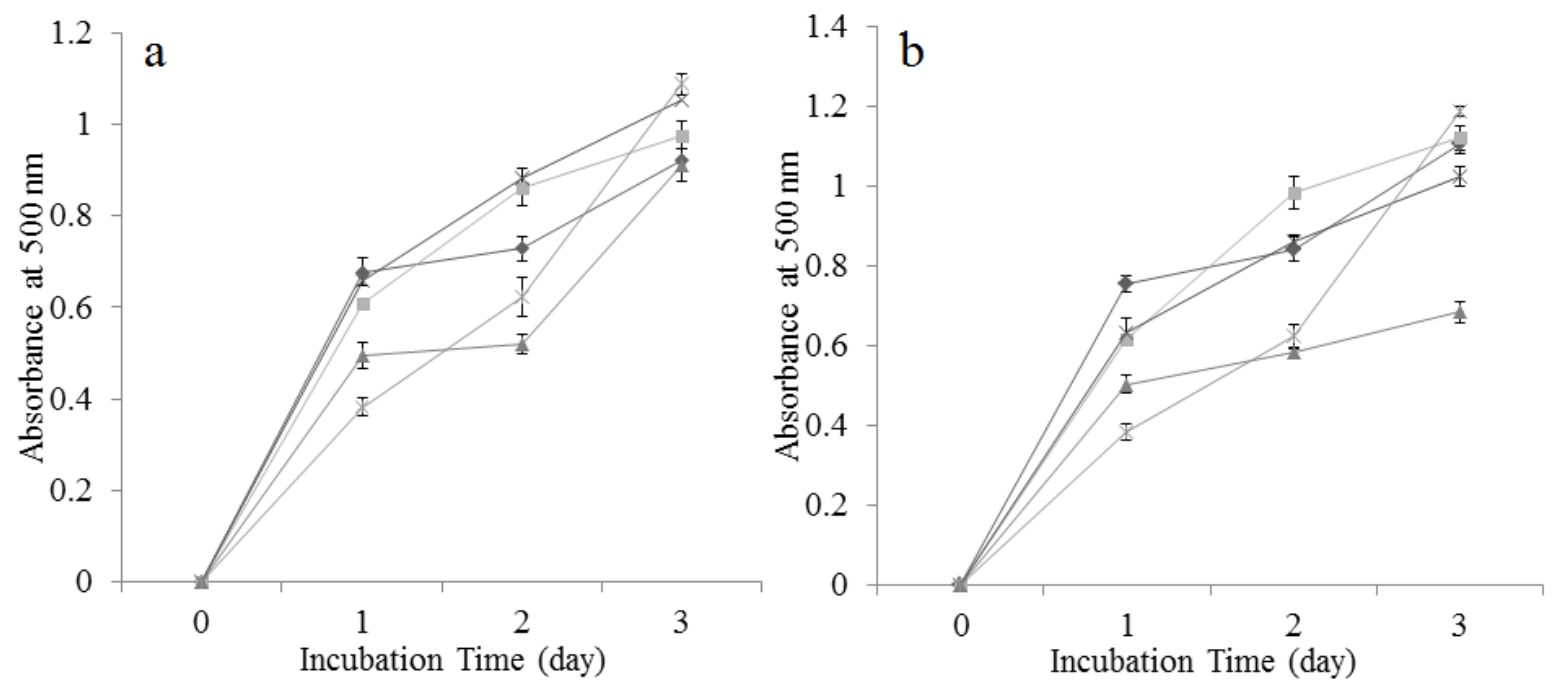

Figure 1: Inhibition of linoleic acid peroxidation activity of methanol and ethanol extracts of pulp of SP (a) PURS

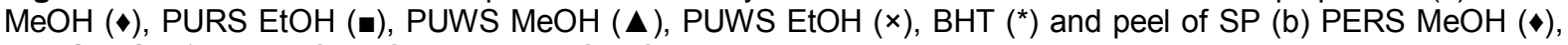
PERS EtOH (ם), PEWS MeOH ( $\mathbf{\Delta})$, PEWS EtOH ( $\times$ ) BHT (*)

extract of PERS in ethanol and methanol showed high absorption, i.e., 1.12 and 1.11, respectively as compared to other sample extracts. Pulp of white SPs and red SPs also showed promising inhibition of linoleic acid peroxidation. BHT showed absorbance 1.2, which was slightly greater than the extract of PERS.

\section{Reducing power activity}

Reducing power is measure of strength to neutralize the free radical moieties. Natural products are commonly assessed for its medicinal values on the bases of their reducing power potential. Figure 2 shows the reducing power of extracts of SP; reducing power of sample is directly proportional to the absorption of visible light at $700 \mathrm{~nm}$. Methanol extract of PEWS showed highest absorbance i.e. 1.45 which is higher than any other extract absorption. However, the methanol and ethanol extracts of PERS showed absorption in the range of 1.19 to 1.45. BHT, which is taken as reference compound showed absorption 1.45 (Figure 2a) while methanol extracts of PUWS and PURS showed absorption 0.58 and 0.2 , respectively (Figure 2b).

\section{Antibacterial activity}

The results of antibacterial activities of peels and pulp of SP extracts against Gram-negative and Gram-positive bacterial strains are shown in Table 4. Multi drug resistant bug, S. aureus was found susceptible to methanol extract of PERS while $B$. subtilis was found susceptible to ethanol extract of PERS. Similarly, promising bactericidal activity of methanol and ethanol extracts of PEWS and PURS were recorded against Grampositive $P$. multocida bacteria.

Most extracts were found least active or completely inactive against Gram-negative bacteria. However, none of the extracts were able to inhibit $E$. coli bacterial growth. 

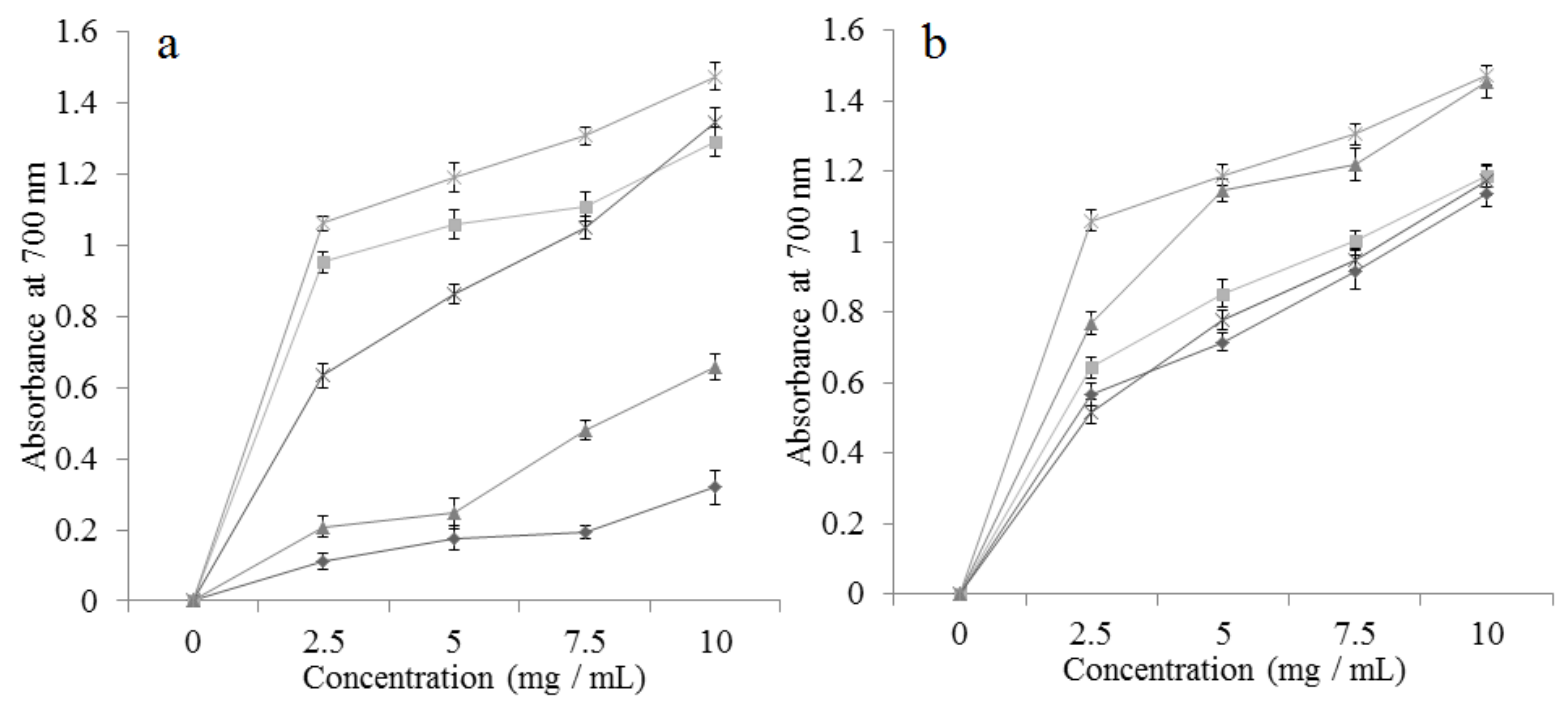

Figure 2: Reducing power activity of methanol and ethanol extracts of pulp of SP (a) PURS MeOH ( $\bullet$ ), PURS $\mathrm{EtOH}(\boldsymbol{\bullet})$, PUWS MeOH $(\mathbf{\Delta})$, PUWS EtOH $(\times)$, BHT $\left.\left({ }^{*}\right)\right)$ and peel of SP (b) pulp PERS MeOH ( $)$, PERS EtOH (匹), PEWS MeOH ( $\mathbf{\Delta})$, PEWS EtOH (×), BHT $\left(^{*}\right)$

Table 4: Antibacterial activity of methanol and ethanol extracts of peels and pulp of red and white variety of SP against Gram-negative and Gram-positive bacteria

\begin{tabular}{|c|c|c|c|c|c|c|c|c|c|}
\hline \multirow[b]{2}{*}{ Bacterial strain } & \multicolumn{9}{|c|}{ Bacterial growth inhibition activity } \\
\hline & $\begin{array}{l}\text { PERS } \\
\text { MeOH }\end{array}$ & $\begin{array}{l}\text { PERS } \\
\text { EtOH }\end{array}$ & $\begin{array}{l}\text { PEWS } \\
\text { MeOH }\end{array}$ & $\begin{array}{l}\text { PEWS } \\
\text { EtOH }\end{array}$ & $\begin{array}{l}\text { PURS } \\
\text { MeOH }\end{array}$ & $\begin{array}{l}\text { PURS } \\
\text { EtOH }\end{array}$ & $\begin{array}{l}\text { PUWS } \\
\text { MeOH }\end{array}$ & $\begin{array}{l}\text { PUWS } \\
\text { EtOH }\end{array}$ & $\begin{array}{c}\text { Positive } \\
\text { control }\end{array}$ \\
\hline Staphylococus aureus & +++ & + & - & + & - & - & + & - & +5 \\
\hline Bacillus subtilis & + & +++ & + & - & - & + & - & - & +5 \\
\hline Escherichia coli & + & + & + & + & + & + & - & - & +5 \\
\hline Pasteurella multocida & + & + & ++++ & ++++ & +++ & +++ & - & + & +5 \\
\hline
\end{tabular}

\section{Antiproliferative activity}

The results of antiproliferative activity using MDBK cancer cell line are shown in Figure 3. Five different concentrations were used to evaluate the antiproliferative activities of peel and pulp extracts of SP. Paclitaxal, an anticancer drug of plant origin which is commonly used in chemotherapeutic procedures of cancer treatment, was taken as positive control. As compared to reference drug, antiproliferative activity of SP extracts were found minimal with some exception such as ethanol extracts of PEWS and PURS that showed anti-proliferative activity at high concentrations.

\section{DISCUSSION}

Many reports that have been published previously demonstrate the medicinal values in terms of antioxidant, antibacterial and antiproliferative potential of plant extracts. In this study, the medicinal potential of two varieties of SP such as white and red SP were investigated for its antioxidant, antibacterial and antiprolifera-

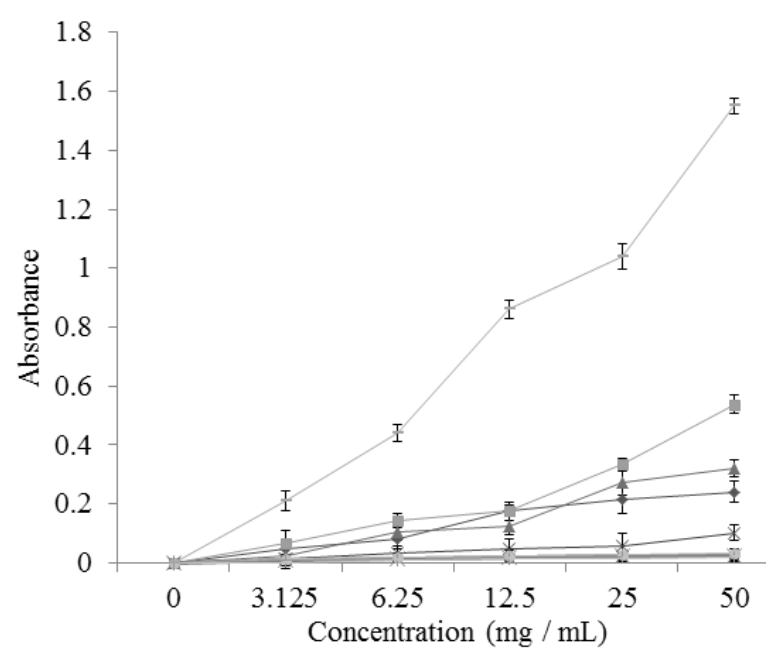

Figure 3: Antiproliferative potential of methanol and ethanol extracts of peel and pulp of red and white variety of SP against MDBK cancer cell line; PERS

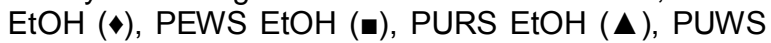
$\mathrm{EtOH}(\times)$, PERS MeOH $\left({ }^{*}\right)$, PEWS MeOH $(\bullet)$, PURS $\mathrm{MeOH}(\mathbf{I})$, PUWS MeOH (-), PEWS EtOH ( $x$ ) and Paclitaxal (-) 
tive activities by extracting bioactive components in methanol and ethanol solvents. Most of the diseases in the human body initiated by the production of free radicals in cell mitochondria during the production of ATP. Free radicals produced as a result of ATP production form reactive oxygen species (ROS) such as the superoxide anion and hydroxyl radicals.

Free radicals play vital role in biological tissues i.e. beneficial and harmful role. Controlled production of these radicals stimulate signaltransduction pathways, phagocytosis and induction of drug detoxification pathways. However, overexpression in the living body can directly influence the cell growth and development, and increase the chance of aging, cancer, pathogenesis of atherosclerosis and several other conditions, including inflammatory disease $[16,17]$. The risk of free radical, however, can be reduced either through avoiding the substances that produce free radicals for example polyunsaturated fats or caloric restriction (depression in ATP production) or increase in intake of antioxidant foods/supplements. Phenolic and flavonoid compounds are known with antioxidant properties [18]. Peels of red SP variety showed promising contents of phenolic and flavonoid compounds which were higher than previously reported for typical potato extract $[19,20]$. Lewis et al reported that the flavonoids content of peel higher than pulp which is in agreement with our study [21]. Antioxidant potential of plant extracts are assessed using different chemical based invitro assays such as DPPH free radical scavenging assay, inhibition of linoleic acid peroxidation assay, reducing power assay, trolox-equivalent antioxidant capacity (TEAC) assay, ABTS assay, and FRAP assay. We in this study picked the DPPH free radical scavenging assay, inhibition of linoleic acid peroxidation assay and reducing power assay to assess the antioxidant activity of extracts. DPPH free radical scavenging potential of PERS in ethanol showed high free radical scavenging activity (90.26 \pm $4.32 \%$ at $100 \mu \mathrm{g} / \mathrm{mL}$ ) which is in agreement of previously reported study [22].

Regarding inhibition of linoleic acid peroxidation, the PERS extracts in ethanol and methanol of both varieties showed $>90 \%$ inhibition whereas standard reference compound, BHT showed 100 $\%$ inhibition which indicates the promising antioxidant potential. It has also been clearly documented that inhibition of linoleic acid peroxidation values as an index of antioxidant capacity of natural sources. It is also reported that purple-leave of SP are abound in quercetin and myricetin, which strongly inhibits lipid peroxidation in addition to scavenge $\mathrm{DPPH}$, hydroxyl, and superoxide free radicals [23].

The reducing power assay is commonly employed to evaluate the electron donation ability of an antioxidant. In human body reduction of oxidants reduces the chance of physical degradation of tissues. Similarly, reducing power activity of PERS extracts in ethanol and methanol revealed promising ability to reduce $\mathrm{Fe}^{+3}$ to $\mathrm{Fe}^{+2}$ which is measured by recording the absorption of the solution at $700 \mathrm{~nm}$. Absorption intensity is directly associated with reducing ability of phenolics or flavonoids.

Microbial infection is a major cause of mortality throughout the world. Natural products have shown critical role in fighting against infection diseases. Screening of antimicrobial potential of plant materials is a key area of phytochemical research. The antibacterial activity of medicinal plants is mainly due to diterpenes, sesquiterpene lactones, alkaloids, flavonoids, triterpenes or naphthoquinones [24]. In this study $P$. multocida was found most susceptible bacterial strain to white and red SP. Multi drug resistance bacterial strain $S$. aureus was found susceptible to PERS extract in methanol while other two strain $B$. subtilis and $E$. coli were found non-susceptible to all extracts except PERS in ethanol which showed promising $B$. subtilis inhibition potential.

The antiproliferative potential of extracts using MDBK cancer cell line indicates negligible activity; however in anticancer campaign natural dietary components have drawn a great attention in reduction of cancer risk. According to one report approximately $60 \%$ anticancer drugs (currently used for cancer therapy) have been developed from natural products [25]. In-vitro biological screening of crude extracts of plant materials or its isolated fractions is a crucial step in finding or developing more effective agents to reduce the oxidative stress, bacterial infection and cancer diseases.

\section{CONCLUSION}

This study reveals that the ethanol peel extract of SP extract delivers greater antioxidant benefits than the pulp although the phenolic and flavonoid contents were found in good quantity in all extracts. Antibacterial activity is satisfactory against $P$. multocida but none of the extracts showed promising antiproliferative activity. Thus, the consumption of peel and pulp extracts of SP may afford health benefits, and also has a potential for development commercially as a nutritional supplement. 


\section{DECLARATIONS}

\section{Acknowledgement}

The authors are thankful to Government College University, Faisalabad and HEC for supporting this study. Furthermore, the authors are grateful to Dr. Nasir Mahmood (Assistant Professor; University of Health Sciences, Lahore) for providing facilities for the anticancer studies. The authors are also grateful to John Mather and Bhatti Information and Management Solutions for editing the manuscript.

\section{Conflict of Interest}

No conflict of interest associated with this work.

\section{Contribution of Authors}

The authors declare that this work was done by the authors named in this article and all liabilities pertaining to claims relating to the content of this article will be borne by them.

\section{Open Access}

This is an Open Access article that uses a funding model which does not charge readers or their institutions for access and distributed under the terms of the Creative Commons Attribution License (http://creativecommons.org/licenses/by/ 4.0) and the Budapest Open Access Initiative (http://www.budapestopenaccessinitiative.org/rea d), which permit unrestricted use, distribution, and reproduction in any medium, provided the original work is properly credited.

\section{REFERENCES}

1. Stefanis L, Burke RE, Greene LA. Apoptosis in neurodegenerative disorders. Curr Opin Neurol 1997; 10: 299-305.

2. Nantitanon, Yotsawimonwat S, Okonogi S. Factors influencing antioxidant activities and total phenolic content of guava leaf extract Witayapan. LWT - Food Sci Technol 2010; 43: 1095-1103.

3. Finkel $T$, Holbrook NJ. Oxidants, oxidative stress and the biology of ageing. Nature 2000; 408: 239-247.

4. Clark AM. Natural products as a resource for new drugs. Pharm Res 1996; 13: 1133-1144.

5. Younes $R N$, Varella $A D$, Suffredini IB. Discovery of new antitumoral and antibacterial drugs from Brazilian plant extracts using high throughput screening. Clinics 2007; 62: 763-768.

6. Diop A. Agricultural Support Systems Division, Calverley $D J B, E d$. Food and Agriculture Organization, Rome, Italy, 1998; $p 38$.
7. FAO (Food and Agriculture Organization). Food and agricultural commodities production. Food and Agriculture Organization of the United Nations; 2011; $p$ 110.

8. Chaovanalikit A, Wrolstad RE. Total Anthocyanins and Total Phenolics of Fresh and Processed Cherries and Their Antioxidant Properties. J Food Sci 2004; 69: 6772.

9. Dewanto $V$, Wu $X$, Adom KK, Liu RH. Thermal processing enhances the nutritional value of tomatoes by increasing total antioxidant activity. J Agric Food Chem 2002; 50: 3010- 3014.

10. Yen GC, Chen HY. Antioxidant Activity of Various Tea Extracts in Relation to Their Antimutagenicity. J Agric Food Chem 1995; 43: 27-32.

11. Khan ZA, Naqvi SAR, Mukhtar A, Hussain Z, Shahzad $S A$, Mansha A, Ahmad M, Zahoor AF, Bukhari $\mathbb{H}$, Janjua MRSA, et. al., Antioxidant and antibacterial activities of Hibiscus Rosa-sinensis Linn flower extracts. Pak J Pharm Sci 2014; 27: 469-474.

12. Sarkar R, Hazra B, Biswas S, Mandal N. Comparative study of the antioxidant and reactive oxygen species scavenging properties in the extracts of the fruits of Terminalia chebula, Terminalia belerica and Emblica officinalis, BMC Complement Alternat Medicin 2010; 10 : 1-15.

13. Mosmann T. Rapid colorimetric assay for cellular growth and survival: Application to proliferation and cytotoxicity assays. J Immunol Methods 1983; 65: 55-63.

14. Padda MS, Picha DH. Quantification of phenolic acids and antioxidant activity in sweet potato genotypes, Sci Horticul 2008; 119: 17-20.

15. Pochapski MT, Fosquiera EC, Esmerino LA, dos Santos EB, Farago PV, Santos FA, Groppo FC. Phytochemical screening, antioxidant, and antimicrobial activities of the crude leaves' extract from Ipomoea batatas (L.) Lam. Pharma Magazin 2011; 7: 165-170.

16. Droge W. Free radicals in the physiological control of cell function. Physiol Rev 2002; 82: 47-95.

17. Salganik $R I$ The benefits and hazards of antioxidants: controlling apoptosis and other protective mechanisms in cancer patients and the human population. J Am Coll Nutr 2001; 20: 464S-472S.

18. Isabel CFR, Ferreira, Baptista P, Vilas-Boas M, Barros L. Free-radical scavenging capacity and reducing power of wild edible mushrooms from northeast Portugal: Individual cap and stipe activity, Food Chem 2007; 100: 1511-1516.

19. Al-Saikhan MS, Howard LR, Miller JC. Antioxidant activity and total phenolics in different genotypes of potato (Solanum tuberosum L.) J Food Sci 1995; 60: 341-343.

20. Kaur C, Kapoor HC. Anti-oxidant activity and total phenolic content of some Asian vegetables. Int J Food Sci Technol 2002; 37: 153-161.

21. Lewis CE, Walker JRL, Lancaster JE, Sutton $K H$. Determination of anthocyanins, flavonoids and phenolic acids in potatoes. I: Coloured cultivars of Solanum tuberosum L. J Sci Food Agric. 1998; 77: 45-57.

Trop J Pharm Res, September 2017; 16(9): 2228 
22. Lee SH, Oh SH, Hwang IG, Kim HY, Woo KS, Woo SH, Kim HS, Lee J, Jeong HS. Antioxidant Contents and Antioxidant Activities of White and Colored Potatoes (Solanum tuberosum L.). Prev Nutr Food Sci 2016; 21: 110-116.

23. Chu YH, Chang CL, Hsu HF. Flavonoid content of several vegetables and their antioxidant activity. J Sci Food Agr 2000; 80: 561-566.
24. Rios JL, Recio MC. Medicinal plants and antimicrobial activity. J Ethnopharm 2005; 100: 80-84.

25. Solowey E, Lichtenstein M, Sallon S, Paavilainen $H$, Solowey E, Galski HL. Evaluating Medicinal Plants for Anticancer Activity. Sci World J 2014; 1-12. 